\title{
Efficacy of Bacillus thuringiensis var. israelensis against malaria mosquitoes in northwestern Burkina Faso
}

Peter Dambach ${ }^{1 *}$, Valérie R Louis ${ }^{1}$, Achim Kaiser ${ }^{2}$, Saidou Ouedraogo ${ }^{3}$, Ali Sié $^{3}$, Rainer Sauerborn ${ }^{1}$ and Norbert Becker 2,4

\begin{abstract}
Background: In Sub Saharan Africa malaria remains one of the major health problems and its control represents an important public health measure. Integrated malaria control comprises the use of impregnated mosquito nets and indoor residual spraying. The use of drugs to treat patients can create additional pressure on the equation of malaria transmission. Vector control may target the adult mosquitoes or their aquatic larval stages. Biological larvicides such as Bacillus thuringiensis israelensis (Bti) represent a promising approach to support malaria control programs by creating additional pressure on the equation of malaria transmission.

Methods: In this study we examined the efficacy of a water-dispersible granule formulation (WDG) of the biological larvicide Bti (VectoBac ${ }^{\oplus}$ ) against wild Anopheles spp. larvae. Different concentrations of the larvicide were tested in standardized plastic tubs in the field against untreated controls. In weekly intervals tubs were treated with fixed concentrations of larvicide and the percentage reduction of larvae and pupae was calculated.

Results: All used concentrations successfully killed 100 percent of the larvae within 24 hours, while the higher concentrations showed a slightly prolonged residual effect. Natural reconolization of larvae took place after two and three days respectively, late instar larvae were not found before 5 days after treatment. For the higher concentrations, up to three days no new larvae were found, implicating that the residual effect of WDG in tropical conditions is approximately one to two days. The overall pupae reduction in treated tubs was $98.5 \%$.

Conclusions: Biological larviciding with Bti can be a promising, additional tool in the fight against malaria in Africa. Environmental particularities in tropical Africa, first and foremost the rapid development of mosquitoes from oviposition to imago have to be taken into account before implementing such counter measures in national or international vector control programs. Nonetheless biological larviciding seems to be an appropriate measure for selected conditions, offering a significant contribution to the future of malaria control.
\end{abstract}

Keywords: Anopheles, Malaria, Bacillus thuringiensis israelensis, Mosquito control, Water dispersible granule, Burkina Faso, West Africa

\section{Background}

Some 40 years after the use of DDT was widely restricted as a universal tool for fighting against the vectors of numerous diseases, first and foremost malaria, larviciding has become an important component in the control of a multitude of vector borne infectious diseases. In its current deployment, however, the types of larvicides

\footnotetext{
* Correspondence: peter.dambach@web.de

${ }^{1}$ Institute of Public Health, University of Heidelberg, Heidelberg, Germany

Full list of author information is available at the end of the article
}

used, shifted towards ecologically sound toxins based on Bacillus thuringiensis israelensis (Bti) and Bacillus sphaericus (Bs), which selectively kill Culicidae larvae and cause no harm for flora and fauna. Being in place for decades in North America, Europe and parts of Asia, larval source management (LSM) based on biological larvicides has rarely left the frame of experimental application in countries of Sub Saharan Africa. Only recently the WHO recommended LSM as a supplemental 
measure, in some environmental settings, to the package of integrated malaria control measures [1].

In contrast to most chemical larvicides $B t i$ has a low resistance potential and virtually no losses in efficacy have been observed in the field following operational use [2-4]. Resistance to $B s$ has been reported [5,6] but seems to play a minor part in field application, in particular when $B s$ is combined with $B t i$.

Depending on the environmental setting, and in particular, the number, size and accessibility of breeding sites, larviciding with $B t i$ can be an important additional tool for vector population control in integrated control programs. In many environmental settings larvae are found in high densities in their respective breeding sites and can be easily accessed, therefore, adult vector populations can be reduced by orders of magnitude with LSM [7-9]. In tropical Africa though, those larvicides have certain limitations and need careful testing under field conditions before being used in vector control. Higher temperatures increase larvicide efficacy, partially due to an increased larval feeding rate $[10,11]$ but may foster biodegradation [12]. Dilution by heavy rainfall, wind drift of surface water and interacting flora and fauna may influence the efficacy and residual activity. In addition the thermal conditions lead to a drastically shortened reproduction cycle of vector mosquitoes, heavily influencing the need for retreatment of breeding sites. Each geographic region features a characteristic combination of those factors and gives reason for testing the larvicide's efficacy under the respective field conditions. It is the first time of testing Bti in that region, which was performed within the framework of a large scale intervention program which uses satellite derived risk maps to predict larval densities [13].

\section{Objective}

To evaluate the effect of larviciding with different concentrations of a Bacillus thuringiensis israelensis strain AM65-52 formulation (Vectobac ${ }^{\circ}$, WDG) on larval populations of wild malaria vectors Anopheles spp., its residual effect and the natural reconolization in semi-field conditions.

\section{Methods}

\section{Study area}

All experiments were performed at the CRSN (Centre de Recherche en Santé de Nouna) research center in Nouna, Northwestern Burkina Faso. The region is characterized as dry orchard savannah with sub-Saharan climate, and an annual mean precipitation of about $800 \mathrm{~mm}$ and a mean temperature of $27.8^{\circ} \mathrm{C}$. The altitude at which the research center is situated, as well as the surrounding is between 250 and $300 \mathrm{~m}$ above sea-level. The area around the small town of Nouna is rural, with most people living from subsistence farming. Malaria incidence in the region is extremely high and shows endemicity with a marked peak during the late rainy season. Despite the strong seasonality, malaria transmission is sustained all year round. The Entomologic Inoculation Rate (EIR), representing the number of infective bites per person per year is around 700 . The region shows a rainy season, usually between June and September and a dry season from November to April with phases of transition in between. Whilst during the rainy season large water accumulations such as rice fields, ponds, brickworks etc. in and around villages act as mosquito breeding sites, the dry season shows a completely different picture. With ceasing rains only few ponds and riverbeds continue bearing water, vegetation is sparse and day temperatures regularly rise above $40^{\circ} \mathrm{C}$. Main vectors for malaria are Anopheles gambiae sl. with more than 98\% and to a much smaller extent $A$. funestus and $A$. nili.

\section{Open field trials}

Two rounds of open field trials were performed between October and December 2012, corresponding to the late rainy season (round 1) and beginning of the dry season (round 2). Twenty plastic tubs with a diameter of $60 \mathrm{~cm}$ were buried into an open field in an array of five rows with 4 tubs each, following the experimental design of Fillinger et al. [4]. Distance between rows was one meter, and between tubs in a row 2 meters. Mud soil and small amounts of typical vegetation from known Anopheles breeding sites were put into each tub, creating a standardized environment with suitable breeding conditions. Tubs were subsequently filled up to initial level with water from a nearby well. Each tub received 25 liters of water, representing an average water depth of 25 centimeters.

Prior to the initial treatment round, 100 field collected Anopheles spp. larvae consisting of 50 first and second instar and 50 third and fourth instar were placed in each tub. Prior to the second treatment round, 70 larvae were placed in each tub, consisting of 35 first and second instar and 35 third and fourth instar. Anopheles spp. larvae were collected from surrounding natural habitats for which earlier studies showed to be more than $95 \%$ Anopheles gambiae s.l..

Bti strain AM65-52 formulation, VectoBac ${ }^{\circ}$ WDG from Valent BioSciences Corp, Illinois, USA with a potency of 3000 ITUs/mg (International Toxic Units), lot number 215-413-PG was used for the treatments. Concentrations were calculated for a standard water depth of $10 \mathrm{~cm}$, given a constant surface area [14]. Concentrations were 0.2; 0.4; 0.8 and $1.0 \mathrm{mg} / \mathrm{l}$, which equals a surface application of $0.2-1.0 \mathrm{~kg} / \mathrm{ha}$. Four tubs in a row received the same concentration or served as control respectively. Initial $B t i$ concentrations were fixed on the basis of earlier studies [4]. 


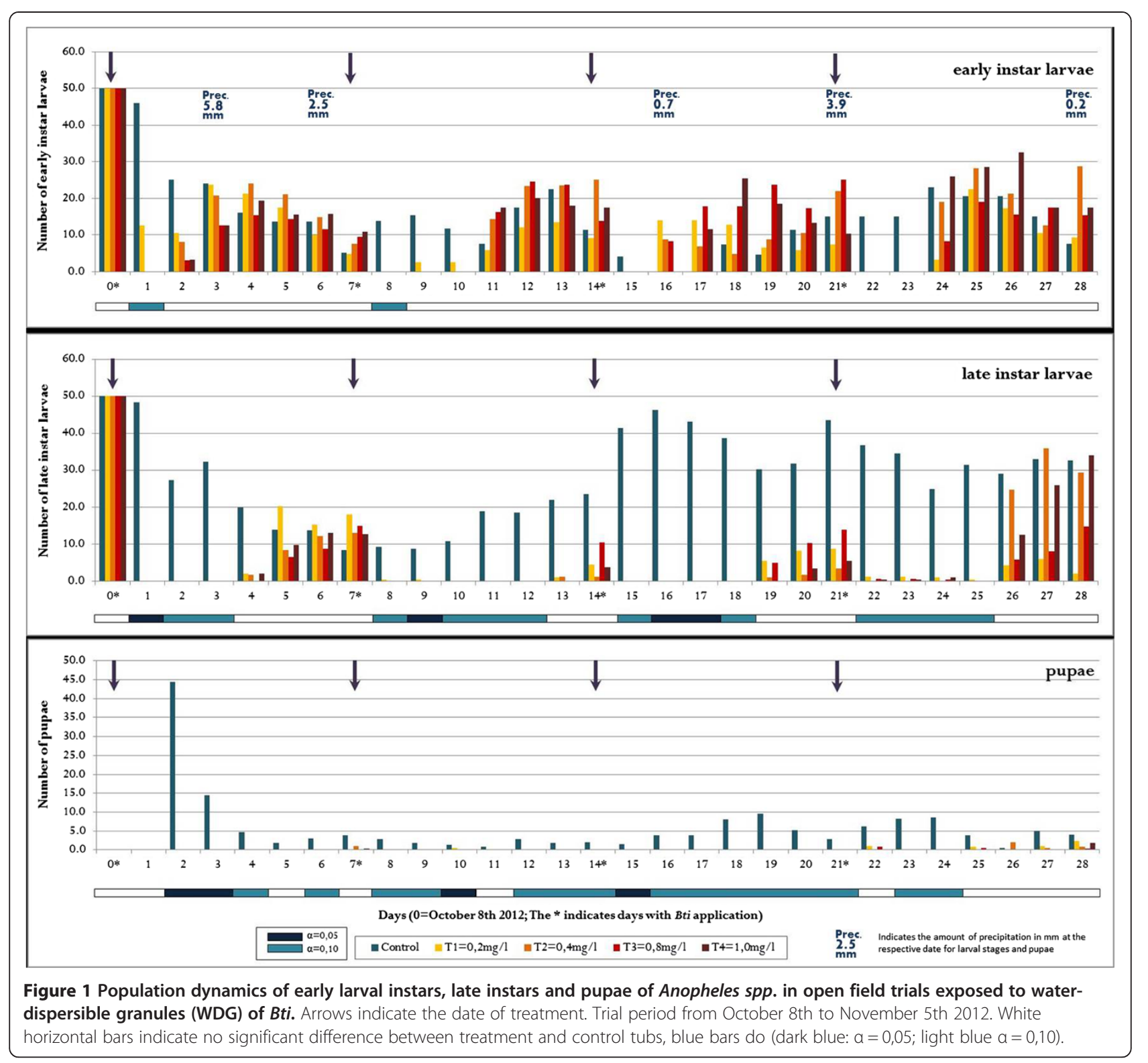

On days $0,7,14$ and 21, $150 \mathrm{ml}$ of WDG formulations in the respective concentration were applied evenly over the water surface to each tub, using a handheld dispenser. During each sampling round of 28 days a daily exhaustive larval count was performed in all 20 tubs, pupae were removed. All larvae were determined to genus level and Anopheles larvae additionally discriminated by larval stage (first and second instar hereafter called early instars, third and fourth instar hereafter called late instars). The percentage reduction in larval numbers was calculated using the formula introduced by Mulla [15], taking into account a natural alteration of mosquito larvae by biotic and abiotic factors in both, the treated and the control sites.

$$
\text { Percentage reduction }=100-\frac{\mathrm{C} 1 \times T 2}{C 2 \times T 1} \times 100
$$

$\mathrm{C} 1$ and $\mathrm{C} 2$ describe the pre and post treatment densities of mosquito larvae in the control group and T1 and $\mathrm{T} 2$ in the pre and post treatment average numbers in the tubs with larvicide application. The values of $\mathrm{C} 1$ and $\mathrm{T} 1$ refer to the initial average numbers of larvae and change on the day of larvicide application. Recoveries of larval populations are shown as a reduction of zero percent, although Mulla's formula would give negative values in this case. This attributes best to describe the efficacy of Bti, which has no effect for values below zero. For the test of statistical significance in larval reduction after Bti treatment, the average number of early instars, late instars, and 


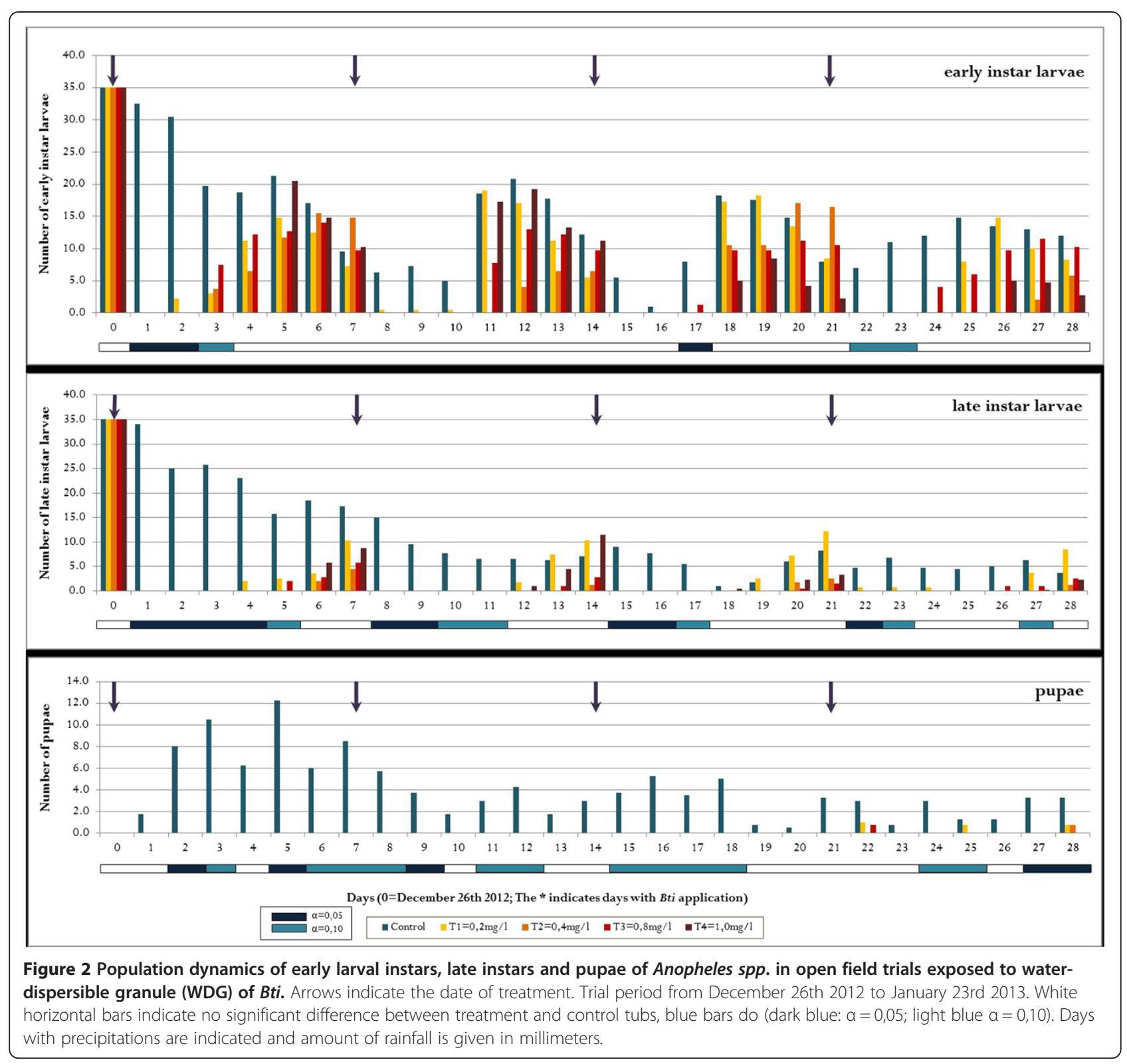

pupae in the control and treatment tubs were compared daily by non-parametric Kruskal-Wallis one-way anova on ranks $(\alpha=0.05$ and 0.1$)$ using SAS 9.2., SAS Institute Inc. Cary. NC USA.

\section{Results}

All concentrations tested showed a $100 \%$ reduction of larvae within the first 24 hours after application. Over time in both rounds (October/November 2012 and December/ January 2012/13) and all sample cycles, natural declines and increases of larval densities were observed in the control and treatment groups. The first round of larvicide application showed reoccurrence of early instars after one to two days. In round two, early instar larvae were found after two days in the lowest concentration of $0.2 \mathrm{mg} / \mathrm{l}$, and after three days in the higher concentrations. After five to six days in rounds one and two respectively, all concentrations showed late instar larvae. Pupae were only found in a small number of cases, mostly towards the end of each assay. During the first 21 days of each round virtually no pupae were found in the treated tubs. Despite the low residual effect of all WDG Bti concentrations of approximately two days and the fast recolonization with Anopheles larvae, the absence of pupae was significant. The overall pupal reduction in treated tubs averaged over both rounds was $98.5 \%$, which is a proxy for the efficacy in reducing the emergence of adult mosquitoes. The second round of open field trials (from December 26th 2012 on) showed generally higher reduction rates and slightly longer residual effects. The lowest concentration 
Table 1 Average number of Anopheles larvae and percentage reduction for different Bti concentrations (VectoBac ${ }^{\circledR}$ WDG) after larvicide application in open field trials from October 08th 2012 on

\begin{tabular}{|c|c|c|c|c|c|c|c|c|c|c|c|c|c|c|c|c|c|c|c|c|c|c|c|}
\hline \multirow[b]{3}{*}{ Day } & \multicolumn{15}{|c|}{ Average number per tub } & \multicolumn{8}{|c|}{ Percentage reduction } \\
\hline & \multicolumn{5}{|c|}{ Early instars } & \multicolumn{5}{|c|}{ Late instars } & \multicolumn{5}{|c|}{ Pupae } & \multicolumn{4}{|c|}{ Early instars } & \multicolumn{4}{|c|}{ Late instars } \\
\hline & $C$ & T1 & $\mathrm{T} 2$ & T3 & T4 & C & T1 & T2 & T3 & T4 & C & T1 & T2 & T3 & T4 & T1 & T2 & T3 & T4 & $\mathrm{T} 1$ & T2 & T3 & T4 \\
\hline $0^{*}$ & 50.0 & & 50.0 & 50.0 & 50.0 & & 50.0 & & 50.0 & 50.0 & & 0.0 & 0.0 & 0.0 & 0.0 & & & & & & & & \\
\hline & 5.0 & & 0 & 0.0 & 0.0 & 48.3 & 0.0 & 0.0 & 0.0 & 0.0 & 0.0 & 0.0 & 0.0 & 0.0 & 0.0 & 73 & 100 & 100 & 100 & 100 & 100 & 100 & 1 \\
\hline & 25.0 & 10.5 & 8.0 & 3.0 & 3.3 & 27.3 & 0.0 & 0.0 & 0.0 & 0.0 & 44.5 & 0.0 & 0.0 & 0.0 & 0.0 & 58 & 68 & 88 & 87 & 100 & 100 & 100 & 10 \\
\hline & & 20.0 & 20.8 & & & & 0.0 & & 0.0 & 0.0 & & 0.0 & 0.0 & 0.0 & 0.0 & 1 & 14 & 48 & 48 & 100 & 100 & 100 & \\
\hline & 16.0 & 21.3 & 24.0 & 15.3 & 19.23 & 20.0 & 2.0 & 1.8 & 0.0 & 2.0 & 4.8 & 0.0 & 0.0 & 0.0 & 0.0 & 0 & 0 & 5 & 0 & 90 & 91 & 100 & 90 \\
\hline & & 17.5 & 21.0 & 14.3 & 15.5 & 14.0 & 20.3 & 8.5 & 6.5 & 9.8 & 1.0 & 0.0 & 0.0 & 0.0 & 0.0 & 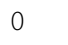 & 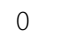 & 0 & . & 0 & 39 & 54 & 30 \\
\hline & 13.7 & 10.0 & 14.8 & 11.5 & 15.8 & 13.7 & 15.3 & 12.3 & 8.8 & 13.0 & 3.0 & 0.0 & 0.0 & 0.0 & 0.0 & 27 & 0 & 16 & 0 & 0 & 10 & 36 & 5 \\
\hline & 5.0 & 4.8 & 7.5 & 9.5 & 10.8 & 8.3 & 18.0 & 13.0 & 15.0 & 12.8 & 3.8 & 0.0 & 1.0 & 0.0 & 0.3 & 5 & 0 & 0 & 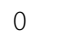 & 0 & 0 & 0 & 0 \\
\hline & 13.8 & 0.0 & 0.0 & 0.0 & 0.0 & 9.3 & 0.5 & 0.0 & 0.0 & 0.0 & L.o & 0.0 & 0.0 & 0.0 & 0.0 & 100 & 100 & 100 & 100 & 97 & 100 & 100 & 1 \\
\hline & 15.3 & 2.5 & 0.0 & 0.0 & 0.0 & 8.8 & 0.5 & 0.0 & 0.0 & 0. & 1.8 & 0.0 & 0.0 & 0.0 & 0.0 & & 100 & 100 & 100 & 97 & 100 & 100 & \\
\hline & 11.8 & & 0.0 & 0.0 & 0.0 & 10.8 & 0.0 & & 0.0 & 0.0 & S. & 0.5 & 0.0 & 0.0 & 0.0 & 78 & 100 & 100 & 100 & 100 & 100 & 100 & 10 \\
\hline & 7.5 & 5.8 & 14.3 & 16.3 & 17.5 & 19.0 & 0.0 & & 0.0 & 0.0 & 0.8 & 0.0 & 0.0 & 0.0 & 0.0 & 19 & 0 & 0 & 0 & 100 & 100 & 100 & 10 \\
\hline & 17.5 & & 23.3 & 24.5 & & 18.5 & 0.0 & & 0.0 & 0.0 & & 0.0 & 0.0 & 0.0 & 0.0 & 28 & 11 & 26 & 47 & 100 & 100 & 100 & \\
\hline & 22.5 & 13.5 & 23.5 & 23.8 & 18.0 & 22.0 & 1.0 & & 0.0 & 0.0 & 1.8 & 0.0 & 0.0 & 0.0 & 0.0 & 37 & 30 & 44 & 63 & 98 & 96 & 100 & 10 \\
\hline$u^{*}$ & 11.3 & 9.0 & 25.0 & 13.8 & & 23.5 & 4.5 & & 10.5 & 3.8 & & 0.0 & 0.0 & 0.0 & 0.0 & 0 & 0 & 0 & 0 & 90 & 96 & 73 & 80 \\
\hline 15 & 4.0 & 0.0 & 0.0 & 0.0 & 0.0 & 41.5 & 0.0 & 0.0 & 0.0 & 0.0 & 1.5 & 0.0 & 0.0 & 0.0 & 0.0 & 100 & 100 & 100 & 100 & 100 & 100 & 100 & \\
\hline & 0.0 & 14.0 & 8.8 & 8.3 & 0.0 & 46.3 & 0.0 & 0.0 & 0.0 & 0. & & 0.0 & 0.0 & 0.0 & 0.0 & 0 & 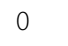 & 0 & 0 & 100 & 100 & 100 & 10 \\
\hline 11 & 0.0 & 14.0 & 6.8 & 17.8 & & 43.3 & 0.0 & & 0.0 & 0.0 & 3.0 & 0.0 & 0.0 & 0.0 & 0.0 & 0 & 0 & 0 & 0 & 100 & 100 & 100 & \\
\hline 8 & 7.3 & 12.8 & 4.8 & 17.8 & 25.5 & 38.8 & 0.0 & 0.0 & 0.0 & 0.0 & 8.0 & 0.0 & 0.0 & 0.0 & 0.0 & 0 & 71 & 0 & 0 & 100 & 100 & 100 & \\
\hline & & & 8.8 & 23.8 & 18.5 & 30.3 & 5.5 & & 5.0 & 0.0 & & 0.0 & 0.0 & 0.0 & 0.0 & o & 13 & 0 & 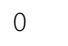 & 5 & 38 & 63 & \\
\hline 20 & 11.3 & 5.8 & 10.5 & 17.3 & 13.3 & 31.8 & 8.3 & 1.8 & 10.3 & 3.5 & 3.3 & 0.0 & 0.0 & 0.0 & 0.0 & 36 & 58 & 0 & 24 & 0 & 0 & 28 & ग1 \\
\hline $21^{*}$ & 15.0 & 7.3 & 22.0 & 25.0 & 10.3 & 43.5 & 8.8 & 3.5 & 14.0 & 5.5 & 28 & 0.0 & 0.0 & 0.0 & 0.0 & 40 & 34 & 0 & 56 & 0 & 0 & 28 & 21 \\
\hline 22 & 15.0 & 0.0 & 0.0 & 0.0 & 0.0 & 36.8 & 1.3 & & 0.8 & 0.5 & & 1.0 & 0.0 & 0.8 & 0.0 & 100 & 100 & 100 & 100 & 82 & 100 & 94 & 09 \\
\hline 23 & 15.0 & 0.0 & 0.0 & 0.0 & 0.0 & 34.5 & 1.3 & 0.0 & 0.8 & 0.5 & 8.3 & 0.0 & 0.0 & 0.0 & 0.0 & 100 & 100 & 100 & 100 & 82 & 100 & 93 & 89 \\
\hline 24 & 23.0 & 3.3 & 19.0 & 8.3 & 26.0 & 25.0 & 1.0 & 0.0 & 0.5 & 1.0 & $0 . J$ & 0.0 & 0.0 & 0.0 & 0.0 & 71 & 44 & 78 & 0 & 80 & 100 & 94 & 60 \\
\hline 25 & 20.5 & 22.5 & 28.3 & 19.0 & 28.5 & 31.5 & 0.5 & 0.0 & 0.0 & 0.0 & 3.8 & 0.8 & 0.0 & 0.5 & 0.0 & 0 & 6 & 44 & 0 & 92 & 100 & 100 & 10 \\
\hline 26 & 20.5 & 17.3 & 21.3 & 15.5 & 32.5 & 29.0 & 4.3 & 24.8 & 5.8 & 12.5 & 0.5 & 0.0 & 2.0 & 0.0 & 0.0 & 0 & 29 & 55 & 0 & 27 & 0 & 38 & 0 \\
\hline 1 & 15.0 & 10.5 & 12.5 & 17.5 & 17.5 & 33.0 & 6.0 & 36.0 & 8.0 & 26.0 & 3.0 & 1.0 & 0.5 & 0.0 & 0.0 & 0 & 43 & 30 & 0 & 10 & 0 & 25 & 0 \\
\hline 28 & 7.5 & 9.3 & 28.8 & 15.3 & 17.5 & 32.8 & 2.0 & 29.5 & 14.8 & 34.0 & 4.0 & 2.3 & 0.8 & 0.3 & 1.8 & 0 & 0 & 0 & 0 & 70 & 0 & 0 & 0 \\
\hline
\end{tabular}

${ }^{*}$ Asterisks indicate days with larvicide application. $C=$ control, $T_{1}=0.2 \mathrm{mg} / \mathrm{l}, \mathrm{T}_{2}=0.4 \mathrm{mg} / \mathrm{l}, \mathrm{T}_{3}=0.8 \mathrm{mg} / \mathrm{l}, \mathrm{T}_{4}=1.0 \mathrm{mg} / \mathrm{l}$.

showed in both rounds a shortened residual effect, which can be observed particularly amongst early instar larvae in the first and second application run. The detailed results are shown in Figure 1, Figure 2, and Table 1, Table 2.

\section{Discussion}

The residual effect varied between less than two days and up to three days, before new first instar larvae were found. The residual effect depends on the concentration of Bti. In both rounds the $0.2 \mathrm{mg} / \mathrm{l}$ concentration showed earlier larval reoccurrence than the others, notably during the first two applications. The fact that after the third and fourth application its efficacy was as good as those of the higher concentrations might have been induced by a slight drop in water levels in the test tubs. The second round of open field trials (from December 26th 2012 on) showed generally higher reduction rates in larval densities and slightly longer residual effects. Contributing factors might be the climatic situation in December, which shows lower air temperatures, decreased insolation and no diluting rainfalls. Increased insolation has been shown to lower the efficacy of Bti [16]; in Burkina Faso where the intensity of sunlight as well as the water temperature is high the potency of Bti formulations can decrease substantially. The lethal concentrations (L95) were much higher than under laboratory conditions. This is likely due to interactions with 
Table 2 Average number of Anopheles larvae and percentage reduction for different Bti concentrations (VectoBac ${ }^{\circledR}$ WDG) after larvicide application in open field trials from December 26th 2012 on

\begin{tabular}{|c|c|c|c|c|c|c|c|c|c|c|c|c|c|c|c|c|c|c|c|c|c|c|c|}
\hline \multirow[b]{3}{*}{ Day } & \multicolumn{15}{|c|}{ Average number per tub } & \multicolumn{8}{|c|}{ Percentage reduction } \\
\hline & \multicolumn{5}{|c|}{ Early instars } & \multicolumn{5}{|c|}{ Late instars } & \multicolumn{5}{|c|}{ Pupae } & \multicolumn{4}{|c|}{ Early instars } & \multicolumn{4}{|c|}{ Late instars } \\
\hline & $\mathrm{C}$ & T1 & $\mathrm{T} 2$ & T3 & T4 & $C$ & T1 & $\mathrm{T} 2$ & T3 & T4 & C & T1 & $\mathrm{T} 2$ & T3 & T4 & T1 & $\mathrm{T} 2$ & T3 & T4 & T1 & $\mathrm{T} 2$ & T3 & T4 \\
\hline$\overline{0^{*}}$ & 35.0 & & 35.0 & 35.0 & & & & & 35.0 & 35.0 & & & 0.0 & 0.0 & 0.0 & & & & & & & & \\
\hline & 35.0 & 0.0 & 0.0 & 0.0 & 0.0 & 34.0 & 0.0 & 0.0 & 0.0 & 0.0 & 1.8 & 0.0 & 0.0 & 0.0 & 0.0 & 100 & 100 & 100 & 100 & 100 & 100 & 100 & \\
\hline & & 23 & 0.0 & 0.0 & 0.0 & 25.0 & 0.0 & 0.0 & 0.0 & 0.0 & 8.0 & 0.0 & 0.0 & 0.0 & 0.0 & 93 & 100 & 100 & 100 & 100 & 100 & 100 & \\
\hline & & 3.0 & 3.8 & 7.5 & & 25.8 & 0.0 & 0.0 & 0.0 & 0.0 & 10.5 & 0.0 & 0.0 & 0.0 & 0.0 & 85 & 81 & 62 & 100 & 100 & 100 & 100 & \\
\hline & 18.8 & 11.3 & 6.5 & 12.3 & 0.0 & 23.0 & 2.0 & 0.0 & 0.0 & 0.0 & 6.3 & 0.0 & 0.0 & 0.0 & 0.0 & 40 & 65 & 35 & 100 & 91 & 100 & 100 & 10 \\
\hline & & & 11.8 & 12.8 & & 15.8 & 2.5 & & 0.0 & 12.3 & 0.0 & 0.0 & 0.0 & 0.0 & 0.0 & 31 & 45 & 40 & 4 & 84 & & 87 & \\
\hline & 17.0 & 1 & 15.5 & 14.0 & & 8.5 & 3.5 & & 2. & 5.8 & 6. & 0.0 & 0.0 & 0.0 & 0.0 & & 9 & $1 \varepsilon$ & 13 & 81 & 89 & 85 & 69 \\
\hline & 9.5 & 7.3 & 14.8 & 9.8 & 10.3 & 17.3 & 10.3 & 4.5 & 5.8 & 8.8 & 8.5 & 0.0 & 0.0 & 0.0 & 0.0 & 24 & 0 & 0 & 0 & 41 & 74 & 67 & 49 \\
\hline & & 0.5 & 0.0 & 0.0 & & 15.0 & 0.0 & 0.0 & 0.0 & $0 . C$ & 5.8 & 0.0 & 0.0 & 0.0 & 0.0 & 90 & 100 & 100 & 100 & 100 & 100 & 100 & 10 \\
\hline & & 0.5 & 0.0 & 0.0 & & 9.5 & 0.0 & 0.0 & 0.0 & 0.0 & 3.8 & 0.0 & 0.0 & 0.0 & 0.0 & 91 & 100 & 100 & 100 & 100 & 100 & 100 & \\
\hline & & 0.5 & 0.0 & 0.0 & & 7.8 & 0.0 & & 0.0 & 0.0 & 1.8 & 0.0 & 0.0 & 0.0 & 0.0 & 87 & & 100 & 100 & 100 & 100 & 100 & \\
\hline & 18.5 & 19.0 & 0.0 & 7.8 & & 6.5 & 0.0 & 0.0 & 0.0 & 0.0 & 3.0 & 0.0 & 0.0 & 0.0 & 0.0 & & 100 & 59 & 14 & 100 & 100 & 100 & 10 \\
\hline & 20.8 & 17.0 & 4.0 & 13.0 & 19.3 & 6.5 & 1.8 & 0.0 & 0.0 & 1.0 & 4.3 & 0.0 & 0.0 & 0.0 & 0.0 & & 88 & 39 & 14 & 55 & & 100 & 70 \\
\hline & 17.8 & 11.3 & 6.5 & 12.3 & & 6.3 & 7.5 & & 1. & 4. & 1.8 & 0.0 & 0.0 & 0.0 & 0.0 & 17 & 76 & 33 & 31 & & 100 & 52 & 0 \\
\hline & 12.3 & & 6.5 & 9.8 & & 7.0 & & & 2.8 & & 3.0 & & & 0.0 & & & 66 & 22 & & 0 & & 0 & 0 \\
\hline & & 0.0 & 0.0 & 0.0 & 0. & 9.0 & 0.0 & 0.0 & 0.0 & 0.0 & 3.8 & 0.0 & 0.0 & 0.0 & 0.0 & 100 & 100 & 100 & 100 & 100 & 100 & 100 & \\
\hline & 1.0 & 0.0 & 0.0 & 0.0 & 0.0 & 7.8 & 0.0 & 0.0 & 0.0 & 0.0 & 5.3 & 0.0 & 0.0 & 0.0 & 0.0 & 100 & 100 & 100 & 100 & 100 & 100 & 100 & \\
\hline & 8.0 & & 0.0 & 1.3 & & 5.5 & 0.0 & & 0.0 & 0.0 & & 0.0 & 0.0 & 0.0 & 0.0 & 100 & 100 & 100 & 100 & 100 & & 100 & \\
\hline 8 & 18.3 & 17.3 & 10.5 & 9.8 & 5.0 & 1.0 & 0.0 & 0.0 & 0.0 & 0.0 & 5.0 & 0.0 & 0.0 & 0.0 & 0.0 & & 0 & 33 & 70 & 100 & 100 & 100 & 70 \\
\hline & 17.5 & & 10.5 & 9.0 & & 1.8 & 2.3 & & 0.0 & 0.0 & 0.0 & & 0.0 & 0.0 & 0.0 & & 0 & 30 & 47 & 2 & & & \\
\hline 0 & 14.8 & 13.5 & 17.0 & 11.3 & 4.3 & 6.0 & 7.3 & 1.8 & 0.5 & 2.3 & 0.5 & 0.0 & 0.0 & 0.0 & 0.0 & & 0 & 4 & 69 & 17 & 0 & 79 & 77 \\
\hline 1 & 8.0 & 8.5 & 16.5 & 10.5 & 2.3 & 8.3 & 12.3 & 2.5 & 1.5 & 3.3 & 32 & 0.0 & 0.0 & 0.0 & 0.0 & & 0 & 0 & 69 & 0 & 0 & 54 & 76 \\
\hline 22 & 7.0 & 0.0 & 0.0 & 0.0 & 0.0 & 4.8 & 0.8 & 0.0 & 0.0 & 0.0 & 3.0 & 1.0 & 0.0 & 0.8 & 0.0 & 100 & 100 & 100 & 100 & 89 & 100 & 100 & \\
\hline 23 & 11.0 & 0.0 & 0.0 & 0.0 & 0.0 & 6.8 & 0.8 & 0.0 & 0.0 & 0.0 & 0.8 & 0.0 & 0.0 & 0.0 & 0.0 & 100 & 100 & 100 & 100 & 100 & 100 & 100 & \\
\hline 24 & 12.0 & 0.0 & 0.0 & 4.0 & 0.0 & 4.8 & 0.8 & 0.0 & 0.0 & 0.0 & 3.0 & 0.0 & 0.0 & 0.0 & 0.0 & 100 & 100 & 75 & 100 & 89 & 100 & 100 & 10 \\
\hline 20 & 14.8 & 8.0 & 0.0 & 6.0 & 0.0 & 4.5 & 0.0 & 0.0 & 0.0 & 0.0 & 1.3 & 0.8 & 0.0 & 0.0 & 0.0 & 49 & 100 & 69 & 100 & 100 & 100 & 100 & 10 \\
\hline 20 & 13.5 & 14.8 & 0.0 & 9.8 & 5.0 & 5.0 & 0.0 & 0.0 & 1.0 & 0.0 & . & 0.0 & 0.0 & 0.0 & 0.0 & 0 & 100 & 45 & 0 & 100 & 100 & 0 & \\
\hline 21 & 13.0 & 10.0 & 2.0 & 11.5 & 4.8 & 6.3 & 3.8 & 0.0 & 1.0 & 0.3 & 3.3 & 0.0 & 0.0 & 0.0 & 0.0 & 28 & 93 & 33 & 0 & 60 & 100 & 12 & 90 \\
\hline 20 & 12.0 & 8.3 & 5.8 & 10.3 & & 3.8 & 8.5 & & 2.5 & 2.3 & 3.3 & 0.8 & 0.8 & 0.0 & 0.0 & 35 & 77 & 35 & 19 & 0 & 0 & 0 & 0 \\
\hline
\end{tabular}

*Asterisks indicate days with larvicide application. $C=$ control, $T_{1}=0,2 \mathrm{mg} / \mathrm{l}, \mathrm{T}_{2}=0,4 \mathrm{mg} / \mathrm{l}, \mathrm{T}_{3}=0,8 \mathrm{mg} / \mathrm{l}, \mathrm{T}_{4}=1,0 \mathrm{mg} / \mathrm{l} \mathrm{Placeholder}$ Table 2 .

mud, vegetation, disturbance by animals and humans, high temperatures, insolation and relocation of surface water by strong winds.

The average water temperature during the first round was $27.1^{\circ} \mathrm{C}$, whilst during the second round it was $25.0^{\circ} \mathrm{C}$. Besides the Bti concentration, environmental conditions seem to have an influence on the larvicide's residual effect [17]. The precipitations occurring during the first round of tests do not seem to have affected the number of captured larvae. Relative air humidity [18] and the number of existing environmental breeding sites [19] have an influence on adult vector survival but did not result in differences in oviposition and hence container recolonization.
The current literature reports highly different findings on the residual effect. Kinde-Gazard \& Baglo [20] reported a period of 9 days before larvae reappeared with a density of $1.4 \%$. Kroeger et al. [21] found in a study carried out in Ecuador and Peru that an effective reduction of larvae was observed up to 7 to 10 days. For Eritrea Shililu et al. [22] described an effect up to two to three weeks. Majambere et al. [23] found first larvae in habitats 4 days after Bti treatment in the Gambia. Our findings are in line with other studies $[4,24,25]$, which found an effect that lasted between two and three days and might be ascribed to a similar experimental setup. Difficulties in comparability of studies arise from different protocols and definitions of 
thresholds of effective larval reductions. Generally it can be distinguished between different study setups, e.g. trials under field, semi-field and laboratory conditions. Discrepancies between studies regarding the residual effect and efficacy may have their origin in the presence or absence of environmental parameters such as vegetation, insolation, and dilution. Furthermore, the definition of larvicidal activity seems inconsistent in literature; sometimes the effect on emerging adult mosquitoes or the reconolization with larvae is researched while other studies see the effect as the larvicide's capability to still kill larvae.

Reapplication with the larvicide solution took place in weekly intervals. Fluctuations in larval densities may have their origin to some percentage in the larval dipping procedure but the biggest share is contributable to the development from one larval stage to another and the oviposition and development of new larvae. While larvae reoccurred within a relatively short time, virtually no pupae were able to develop between two Bti applications. Within the weekly intervention intervals late instar larvae were not capable of developing into pupae and imagines. Despite the short residual effect of all WDG Vectobac ${ }^{\circ}$ Bti concentrations of approximately two days and the fast recolonization with larvae of all genera, the lack of pupae is significant and can be seen as the most important indicator for the efficacy of larviciding interventions [25]. We would suggest carrying out further studies to examine the possibility of decreasing the reapplication rates to longer intervals. Our observations of very low numbers of pupae towards the end of the treatment intervals might be an indicator for a prolonged protective effect of new adult mosquito emergence. Some studies indicate that after longer periods of continuous larvicide application the reconolization with larvae decreases. Nonetheless, further testing for the local appropriateness of application and persistence of other Bti formulations (e.g. VectoMax ${ }^{\circ}$ ) should be undertaken. Due to the conservation of natural aquatic predators attributable to the selective mode of action of $B t i$ a permanent reduction of newly emerging larvae can be achieved and might result in a permanent residual control effect. Extensively used in many parts of the world, biological larviciding is to date sparsely implemented in African malaria control programs.

\section{Conclusions}

The study shows that the WDG Bti formulation even at a very low dosage of $0.2 \mathrm{~kg} / \mathrm{ha}$ is highly effective against the main malaria vector larvae in Burkina Faso, offering viable possibilities for larviciding in climatic and environmental conditions of tropical Africa. However, the observed short persistence might require frequent retreatment of breeding sites. Bti is a promising complimentary tool for integrated malaria control strategies for specific settings and future formulations with enhanced activity and persistence may extend its area of deployment as well as its cost effectiveness.

\section{Competing interests}

The authors declare that they have no competing interests.

\section{Authors' contributions}

Conceived and designed the experiments: PD, NB, SO, AK. Performed the experiments: SO, PD. Analyzed the data: PD, VL, AK. Wrote the paper: PD, $\mathrm{VL}, \mathrm{AK}, \mathrm{SO}, \mathrm{AS}, \mathrm{RS}, \mathrm{NB}$. All authors read and approved the final manuscript.

\section{Acknowledgements}

We gratefully thank the team of entomologists and fieldworkers at the research site in Nouna Burkina Faso that helped with the conceptualization and conduction of the study. Furthermore, we would like to thank Peter DeChant for his valuable input to the study concept.

\section{Author details}

${ }^{1}$ Institute of Public Health, University of Heidelberg, Heidelberg, Germany. ${ }^{2}$ German Mosquito Control Association (KABS), Speyer, Germany. ${ }^{3}$ Centre de Recherche en Santé de Nouna (CRSN), Nouna, Burkina Faso. ${ }^{4}$ Centre for Organismal Studies, University of Heidelberg, Heidelberg, Germany.

Received: 14 April 2014 Accepted: 29 July 2014

Published: 15 August 2014

\section{References}

1. WHO: WHO World Malaria Report 2012. 2013.

2. Becker N, Petric D, Zgomba M, Boase C, Madon M, Dahl C, Kaiser A: Mosquitoes and Their Control. Heidelberg, Germany: Springer; 2010.

3. Brogdon WG, MCAllister JC: Insecticide resistance and vector control. Emerg Infect Dis 1998, 4:605-613.

4. Fillinger U, Knols BGJ, Becker N: Efficacy and efficiency of new Bacillus thuringiensis var. israelensis and Bacillus sphaericus formulations against Afrotropical anophelines in Western Kenya. Trop Med Int Health 2003, 8:37-47.

5. Nielsen-Leroux C, Charles JF, Thiéry I, Georghiou GP: Resistance in a laboratory population of Culex quinquefasciatus (Diptera: Culicidae) to Bacillus sphaericus binary toxin is due to a change in the receptor on midgut brush-border membranes. Eur J Biochem FEBS 1995, 228:206-210.

6. Rao DR, Mani TR, Rajendran R, Joseph AS, Gajanana A, Reuben R: Development of a high level of resistance to Bacillus sphaericus in a field population of Culex quinquefasciatus from Kochi, India. J Am Mosa Control Assoc 1995, 11:1-5.

7. Walker K, Lynch M: Contributions of Anopheles larval control to malaria suppression in tropical Africa: review of achievements and potential. Med Vet Entomol 2007, 21:2-21.

8. Killeen GF, Fillinger U, Knols BGJ: Advantages of larval control for African malaria vectors: low mobility and behavioural responsiveness of immature mosquito stages allow high effective coverage. Malar J 2002, 1:8.

9. Fillinger $U$, Lindsay SW: Suppression of exposure to malaria vectors by an order of magnitude using microbial larvicides in rural Kenya. Trop Med Int Health 2006, 11:1629-1642.

10. Rasnitsyn SP, Voitsik AA, lasiukevich W: The effect of water temperature on the action of bacterial insecticides against mosquito larvae. Med Parazitol (Mosk) 1993, (1):8-10.

11. Mittal PK, Adak T, Sharma VP: Effect of temperature on toxicity of two bioinsecticides spherix (Bacillus sphaericus) and bactoculicide (Bacillus thuringiensis) against larvae of four vector mosquitoes. Indian J Malariol 1993, 30:37-41.

12. Nayar JK, Knight JW, Ali A, Carlson DB, O'Bryan PD: Laboratory evaluation of biotic and abiotic factors that may influence larvicidal activity of Bacillus thuringiensis serovar. israelensis against two Florida mosquito species. J Am Mosa Control Assoc 1999, 15:32-42.

13. Dambach P, Machault V, Lacaux J-P, Vignolles C, Sié A, Sauerborn R: Utilization of combined remote sensing techniques to detect environmental variables influencing malaria vector densities in rural West Africa. Int J Health Geogr 2012, 11:8. 
14. Schnetter W, Engler S, Morawcik J, Becker N: Wirksamkeit von Bacillus thuringiensis var. israelensis gegen Stechmuecken und Nontarget Organismen. Mitt D Ges allg ang Entomol 1981, 2:195-202.

15. Mulla MS, Norland LR, Fanara DM, Darwazeh HA, Mickean DW: Control of Chironomid Midges1 in Recreational Lakes2,3. J Econ Entomol 1971, 64:300-307.

16. Becker $\mathrm{N}$ : Community participation in the operational use of microbial control agents in mosquito control programs. Bull Soc Vector Ecol 1992, 17:114-118

17. Mittal PK: Biolarvicides in vector control: challenges and prospects. JVector BorneDis 2003, 40(0972-9062 (Print)):20-32.

18. Yamana TK, Eltahir EAB: Incorporating the effects of humidity in a mechanistic model of Anopheles gambiae mosquito population dynamics in the Sahel region of Africa. Parasit Vectors 2013, 6:235.

19. Govoetchan R, Gnanguenon V, Ogouwalé E, Oké-Agbo F, Azondékon R, Sovi A, Attolou R, Badirou K, Youssouf RA, Ossè R, Akogbéto M: Dry season refugia for anopheline larvae and mapping of the seasonal distribution in mosquito larval habitats in Kandi, northeastern Benin. Parasit Vectors 2014, 7:137.

20. Kinde-Gazard D, Baglo T: Assessment of microbial larvicide spraying with Bacillus thuringiensis israelensis, for the prevention of malaria. Médecine Mal Infect 2012, 42:114-118.

21. Kroeger A, Horstick O, Riedl C, Kaiser A, Becker N: The Potential for Malaria Control with the Biological Larvicide Bacillus-Thuringiensis Israelensis (Bti) in Peru and Ecuador. Acta Trop 1995, 60:47-57.

22. Shililu Jl, Tewolde GM, Brantly E, Githure Jl, Mbogo CM, Beier JC, Fusco R, Novak RJ: Efficacy of Bacillus thuringiensis israelensis, Bacillus sphaericus and temephos for managing Anopheles larvae in eritrea. J Am Mosa Control Assoc 2003, 19:251-258.

23. Majambere S, Lindsay SW, Green C, Kandeh B, Fillinger U: Microbial larvicides for malaria control in The Gambia. MalarJ 2007, 6(1475-2875 (Electronic)):76.

24. Nartey R, Owusu-Dabo E, Kruppa T, Baffour-Awuah S, Annan A, Oppong S, Becker N, Obiri-Danso K: Use of Bacillus thuringiensis var israelensis as a viable option in an Integrated Malaria Vector Control Programme in the Kumasi Metropolis. Ghana. Parasit Vectors 2013, 6:116.

25. Su T, Mulla MS: Field evaluation of new water-dispersible granular formulations of Bacillus thuringiensis ssp. israelensis and Bacillus sphaericus against Culex mosquitoes in microcosms. J Am Mosq Control Assoc 1999, 15:356-365.

doi:10.1186/1756-3305-7-371

Cite this article as: Dambach et al:: Efficacy of Bacillus thuringiensis var. israelensis against malaria mosquitoes in northwestern Burkina Faso.

Parasites \& Vectors 2014 7:371

\section{Submit your next manuscript to BioMed Central and take full advantage of:}

- Convenient online submission

- Thorough peer review

- No space constraints or color figure charges

- Immediate publication on acceptance

- Inclusion in PubMed, CAS, Scopus and Google Scholar

- Research which is freely available for redistribution 